\title{
Peningkatan pertumbuhan Shorea balangeran Korth. di hutan Kampus Universitas Palangka Raya
}

\author{
E. R. Sinaga ${ }^{1}$, J. M. Rotinsulu ${ }^{1}$, P. E. Putir ${ }^{1}$ \\ 1Jurusan Kehutanan, Universitas Palangka Raya, Palangka Raya, Kalimantan Tengah, Indonesia
}

\begin{abstract}
Abstrak.
Balangeran (Shorea balangeran Korth.) merupakan tanaman yang habitat tumbuhnya di lahan gambut, tetapi keberadaan tanaman ini mulai terancam punah. Penelitian ini bertujuan untuk menganalisis pertumbuhan Shorea balangeran Korth. dengan pemberian pupuk tunggal N, P dan K di Hutan Kampus Universitas Palangka Raya. Diharapkan hasil dari penelitian ini memberikan informasi awal mengenai pertumbuhan Balangeran dengan jenis pupuk yang berbeda sebagai pertimbangan untuk rehabilitasi di lahan gambut. Pengamatan dan pengumpulan data dilakukan menggunakan metode jalur, sedangkan pemberian pupuk dilakukan dengan metode acak. Objek penelitian anakan Balangeran yang berumur 7 (tujuh) bulan, dengan 3 (tiga) perlakuan: Urea (P1), SP-36 (P2), dan $\mathrm{KCl}(\mathrm{P} 3)$. Untuk mengevaluasi pertumbuhan, variabel yang diukur adalah tinggi, diameter dan pertambahan jumlah daun. Hasil penelitian menunjukkan bahwa pertumbuhan Balangeran berdasarkan tinggi (1,26 $\mathrm{cm})$ dan diameter rata-rata $(0,044 \mathrm{~cm})$ dengan pemberian pupuk P (SP-36) lebih baik dibandingkan dengan pemberian pupuk Urea $(1,18 \mathrm{~cm}$ dan $0,033 \mathrm{~cm})$, dan $\mathrm{KCl}$ $(1,14 \mathrm{~cm}$ dan $0,038 \mathrm{~cm})$, demikian pula dengan variabel pertambahan jumlah daun. Dapat disimpulkan bahwa untuk memacu pertumbuhan Balangeran yang ditanam di lapangan, lebih baik pertumbuhannya dengan menambahkan unsur Fosfor daripada pupuk SP-36 dengan dosis tertentu. Selain itu dapat menjadi bahan pertimbangan untuk mengembangkan tanaman Balangeran di lahan gambut.
\end{abstract}

Kata kunci: balangeran, lahan gambut, pupuk

\begin{abstract}
.
Balangeran (Shorea balangeran Korth.) is a plant that usually growth in peatlands habitat. But this plant existence start endangered. This research purposed to analyze the growth of Shorea balangeran korth. by giving a singular fertilizer of $N, P$ and $K$ at the University of Palangka Raya Forest. Result of this research can be regarded as the initial information of the growth Balangeran with different fertilizer as consideration for rehabilitation in peatlands. Observations and data collection used track methods while fertilizer addition was done by random methods. Research object was 7 months old Balangeran, with 3 (three) treatment: Urea (P1), SP-36 (P2), and $\mathrm{KCl}(\mathrm{P} 3)$. To evaluate the growth, measurement of height, diameter and number of leaves were performed. The results showed that height (1.26 $\mathrm{cm})$ and average diameter $(0.044 \mathrm{~cm})$ with fertilizer $P(S P$ 36) addition were better than the provision of Urea fertilizer $(1,18 \mathrm{~cm}$ and $0,033 \mathrm{~mm})$, and $\mathrm{KCl}(1,14 \mathrm{~cm}$ and $0,038 \mathrm{~cm})$, as well as number of leaves. It can be concluded that to stimulate growth of Balangeran planted at the field, the addition of pospor of fertilizer SP-36 showed better result.
\end{abstract}

Keywords: balangeran, peat land, fertilizer

\section{PENDAHULUAN}

Ekosistem gambut memberikan manfaat yang sangat luas bagi kehidupan di muka bumi karena merupakan habitat berbagai flora dan fauna serta berperan sebagai pengatur tata air, sehingga daerah sekitarnya dapat terhindar dari intrusi air laut pada saat musim kemarau dan tercegah dari banjir saat musim hujan. Lahan dan hutan gambut mampu menyimpan dan menyerap gas rumah kaca karbon dalam jumlah besar sehingga secara tidak langsung juga berperan penting dalam mengatur iklim.

\footnotetext{
${ }^{*}$ Korespondensi Penulis

Email : esraririssinaga@gmail.com
} 
Berbagai jenis tumbuhan yang sering dijumpai di lahan gambut di antaranya Balangeran, jenis Balangeran memiliki nilai komersial tinggi. Namun akibat penebangan yang tidak terkendali, keberadaan jenis ini kini terancam punah. Kemampuan menyesuaikan dengan lingkungan serta kemampuan untuk hidup Balangeran di lapangan cukup tinggi karena Balangeran merupakan salah satu jenis asli Kalimantan (Suryanto et al. 2012), tetapi kondisi pohon induk Balangeran saat ini di hutan alam terancam keberadaannya disebabkan penebangan yang berlebihan, konversi lahan, dan kebakaran hutan, sedangkan pembudidayaan Balangeran masih kurang diminati karena masa tebang yang lama.

Salah satu usaha meningkatkan pertumbuhan tanaman adalah dengan perbaikan mutu tanaman. Pada saat ini cara yang dilaksanakan yaitu dengan pemberian pupuk tunggal karena lebih mudah didapatkan dan harganya relatif lebih murah. Berdasarkan hal tersebut, maka dilakukan pengamatan untuk melihat pengaruh penambahan unsur hara berupa pemberian pupuk tunggal $\mathrm{N}$, $\mathrm{P}$ dan K terhadap pertumbuhan tanaman.

Areal Hutan Kampus Universitas Palangka Raya merupakan salah satu areal yang membudidayakan tanaman Balangeran, namun belum pernah dilakukan penelitian mengenai pertumbuhan dengan pemberian pupuk tunggal. Penelitian ini untuk menganalisis pertumbuhan anakan Balangeran pada pemberian pupuk tunggal ( $\mathrm{N}, \mathrm{P}$ dan $\mathrm{K}$ ) dan menentukan jenis pupuk yang dapat meningkatkan pertumbuhan anakan di areal penanaman.

\section{METODOLOGI}

\subsection{Lokasi kajian dan waktu penelitian}

Penelitian ini dilaksanakan pada hutan kampus di areal penanaman Kebun Bibit Rakyat (KBR) yang terletak di Jalan Yos Sudarso. Penelitian dilakukan \pm 4 bulan, dimulai pada bulan Maret sampai dengan Juni 2017.

\subsection{Alat dan bahan}

Alat yang digunakan dalam penelitian ini adalah cangkul, parang, pita meter, caliper, timbangan, alat tulis dan alat dokumentasi. Bahan yang digunakan dalam penelitian ini pupuk tunggal N, P dan $\mathrm{K}$ dengan dosis 20 gr dan anakan Balangeran (Shorea balangera Korth.) yang berumur 7 bulan sebanyak 200 anakan.

\subsection{Prosedur kerja}

Jalur pengamatan sebanyak 5 jalur, pada setiap jalur tanaman terdapat 40 tanaman, banyaknya perlakuan per jalur yaitu 4 perlakuan, setiap perlakuan diambil anakan sebanyak 10 tanaman per jalur sehingga total keseluruhan 
anakan yang digunakan pada penelitian ini sebanyak 200 anakan. Pembersihan jalur dan pembuatan guludan pada lokasi. Pada masing-masing anakan diberi pita sebagai penanda untuk menghindari kesalahan dalam pengambilan data. Pupuk ditimbang dengan dosis $20 \mathrm{gr} /$ tanaman. Perlakuan, pemberian pupuk dilakukan dengan cara membuat lubang sedalam $15 \mathrm{~cm}$ dan jarak radius $20 \mathrm{~cm}$ dari tanaman.

Tinggi tanaman diukur dari permukaan media (batas antara pangkal tanaman dengan tanah) sampai pada titik tumbuh tanaman (tempat keluarnya daun muda). Pengukuran dilakukan 2 minggu sekali dengan menggunakan pita meter. Diameter tanaman diukur pada pangkal batang atau kurang lebih $1 \mathrm{~cm}$ di atas tanah/media. Pengukuran dilakukan 2 minggu sekali dengan menggunakan caliper. Pengamatan pertambahan jumlah daun dilakukan setiap 1 bulan sekali. Pemeliharaan terhadap anakan yaitu pembersihan sekitar tanaman dan penyiraman, pemeliharaan dilakukan sampai pengukuran terakhir.

\subsection{Rancangan penelitian}

Penelitian ini menggunakan metode Rancangan Acak Kelompok (RAK) dengan 4 perlakuan dan masing-masing 10 kali pengulangan. Perlakuan disusun sebagai berikut :

P0 = Tanpa pemupukan dengan dosis 0 gr/tanaman

$\mathrm{P} 1=$ Pemupukan $\mathrm{N}$ dengan dosis $20 \mathrm{gr} / \mathrm{tanaman}$

P2 = Pemupukan P dengan dosis $20 \mathrm{gr} /$ tanaman

P3 = Pemupukan $\mathrm{K}$ dengan dosis $20 \mathrm{gr} /$ tanaman

Adapun model rancangan acak kelompok adalah sebagai berikut:

$Y i j=\mu+\tau i+\beta j+E i j$

dimana: $i=1,2, \ldots, t$ dan $j=1,2, \ldots, r$

Yij = Pengamatan pada perlakuan ke-i dan ulangan ke-j

$\mu \quad=$ Rerata umum

$\tau \mathrm{i} \quad=$ Pengaruh aditif dari perlakuan ke-i

$\beta \mathrm{j} \quad=$ Pengaruh aditif dari kelompok ke-j

Eij = Pengaruh acak pada perlakuan ke-i ulangan ke

\subsection{Analisis data}

Analisis data dilakukan terhadap rata-rata pertambahan tinggi tanaman, rata-rata pertambahan diameter dan rata-rata pertambahan jumlah daun, dengan menggunakan analisis varian (sidik ragam). Data yang menunjukkan pengaruh nyata terhadap perlakuan pemberian pupuk, maka dilanjutkan dengan uji lanjut. Pengolahan data dilakukan dengan Microsoft Excel. 


\section{HASIL DAN PEMBAHASAN}

\subsection{Hasil}

\subsubsection{Pertumbuhan tinggi}

Data pengukuran rata-rata pertambahan tinggi anakan Balangeran selama penelitian ditunjukkan pada Gambar 1.

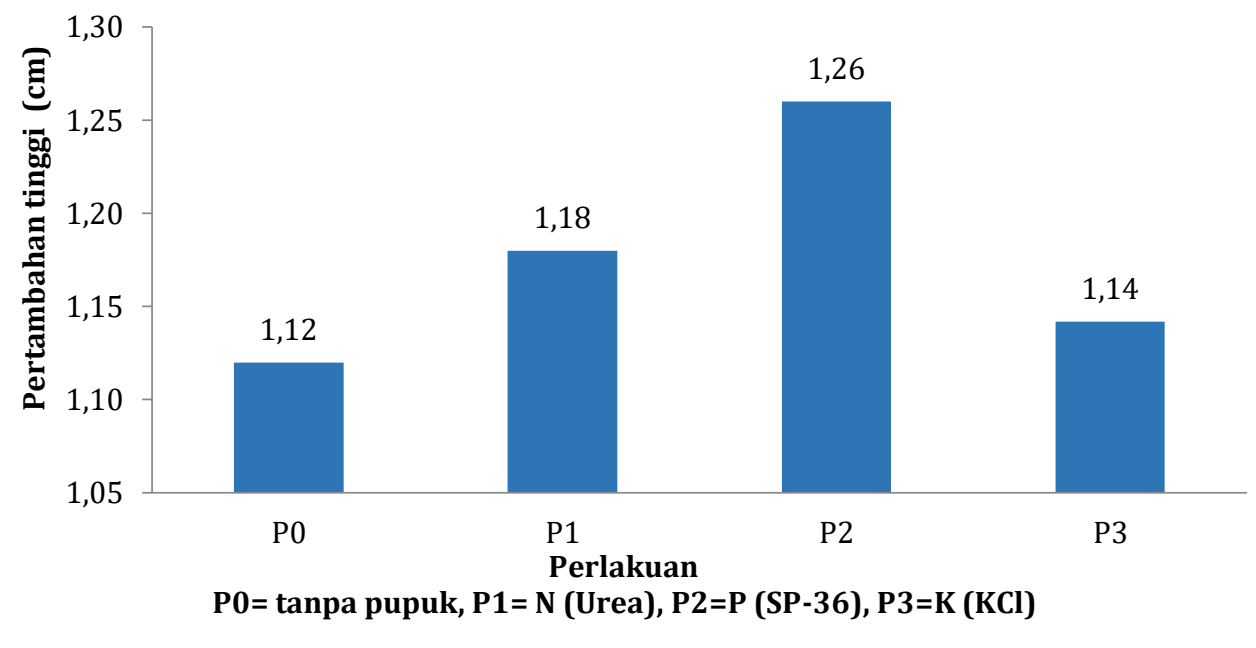

Gambar 1. Rata-rata tinggi tanaman Shorea balangeran Korth.

Berdasarkan Gambar 1, pemberian pupuk jenis P (P2) menunjukkan ratarata tinggi tanaman yang tertinggi yakni $1,26 \mathrm{~cm}$, kemudian diikuti pemberian jenis $N(P 1)$ sebesar 1,18 cm dan jenis $K(P 3)$ sebesar $1,14 \mathrm{~cm}$, sedangkan tanpa pemberian pupuk menunjukkan rata-rata tinggi tanaman terendah. Hal ini menunjukkan bahwa pemberian pupuk mampu meningkatkan rata-rata tinggi tanaman yang lebih baik dibandingkan tanpa pemberian pupuk.

Hasil pengujian anova pengaruh pemberian beberapa jenis pupuk terhadap tinggi Balangeran dapat dilihat pada Tabel 1.

Tabel 1. Anova pertambahan tinggi anakan Balangeran.

\begin{tabular}{lcccccc}
\hline \multicolumn{1}{c}{$\begin{array}{c}\text { Sumber } \\
\text { Keragaman }\end{array}$} & $\begin{array}{c}\text { Derajat } \\
\text { Bebas } \\
\text { (DB) }\end{array}$ & $\begin{array}{c}\text { Jumlah } \\
\text { Kuadrat } \\
\text { (JK) }\end{array}$ & $\begin{array}{c}\text { Kuadrat } \\
\text { Tengah } \\
\text { (KT) }\end{array}$ & F Hitung & $5 \%$ & $1 \%$ \\
\hline Kelompok & 4 & 0,956 & 0,239 & $11,447^{* *}$ & 3,84 & 7,01 \\
Perlakuan & 2 & 0,036 & 0,018 & $0,868^{\text {tn }}$ & 4,46 & 8,65 \\
Galat & 8 & 0,167 & 0,020 & & & \\
Total & 14 & 1,159 & & & & \\
\hline
\end{tabular}

Sumber : Data primer

Keterangan:

**: berpengaruh sangat nyata

tn: tidak berpengaruh nyata 
Tabel 1 menunjukkan bahwa pengelompok tanaman berpengaruh sangat nyata yakni $\mathrm{F}$ hitung $>\mathrm{F}$ tabel pada taraf $5 \%$ dan 1\%, sedangkan perlakuan pemberian pupuk tidak berpengaruh nyata dalam pertambahan tinggi anak Balangeran.

Berdasarkan Tabel 1, maka perlu dilakukan uji lanjut BNJ untuk mengetahui perbedaan antara semua pasangan kelompok yang memiliki pengaruh nyata terhadap pertambahan tinggi Balangeran. Interaksi antara kelompok dan nilainya dapat dilihat pada Tabel 2.

Tabel 2. Uji Lanjut BNJ pertambahan tinggi anakan Balangeran.

\begin{tabular}{c|cccccc}
\hline \multicolumn{2}{c}{ Kelompok } & 1 & 2 & 3 & 4 & 5 \\
\cline { 3 - 7 } \multicolumn{2}{l}{ Nilai Tengah } & 1,14 & 1,04 & 0,99 & 1,69 & 1,12 \\
\cline { 3 - 7 } 1 & 1,14 & - & & & & \\
2 & 1,04 & $0,10^{\text {tn }}$ & - & & & \\
3 & 0,99 & $0,15^{\text {tn }}$ & $0,05^{\text {tn }}$ & - & & \\
4 & 1,69 & $0,55^{*}$ & $0,65^{*}$ & $0,70^{* *}$ & - & - \\
5 & 1,12 & $0,02^{\text {tn }}$ & $0,08^{\text {th }}$ & $0,13^{\text {tn }}$ & $0,57^{\text {tn }}$ & \\
\hline
\end{tabular}

Sumber : data primer

Keterangan:

** : berbeda sangat nyata

* : berbeda nyata

tn : tidak berbeda nyata

Uji lanjutan BNJ pada Tabel 2 menunjukkan bahwa nilai selisih perlakuan yang memiliki pengaruh berbeda sangat nyata yaitu kelompok $3-4=0,70$, kemudian kelompok $2-4=0,65$, untuk yang berpengaruh berbeda nyata kelompok 1 - 4 sebesar 0,55, sedangkan pasangan lainnya tidak berpengaruh nyata.

\subsubsection{Pertumbuhan diameter tanaman}

Rata-rata pertambahan tinggi anakan Balangeran pada setiap variasi pupuk dapat dilihat pada Gambar 2. Pemberian pupuk jenis P (P2) menunjukkan rata-rata diameter tanaman yang tertinggi yakni $0,044 \mathrm{~cm}$, kemudian diikuti pemberian jenis $\mathrm{K}$ (P3) sebesar 0,038 cm dan tanpa dipupuk sebesar $0,035 \mathrm{~cm}$, sedangkan pemberian pupuk $\mathrm{N}$ (P1) menunjukkan rata-rata tinggi tanaman terendah. Hal ini menunjukkan bahwa pemberian pupuk mampu meningkatkan rata-rata diameter tanaman 2. 


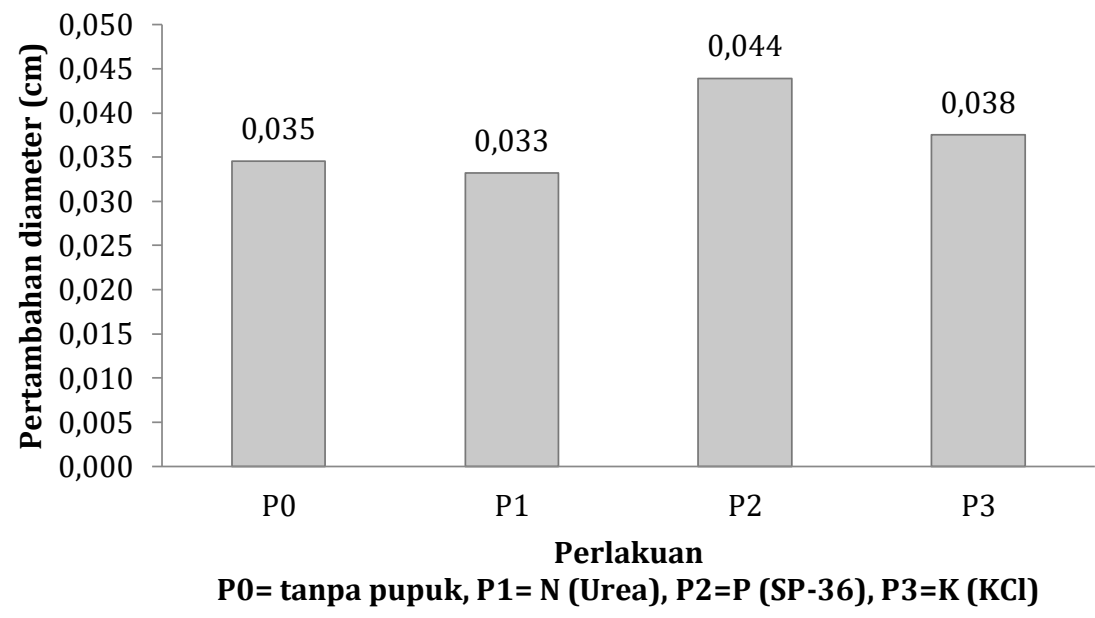

Gambar 2. Pertambahan rata-rata diameter anakan Balangeran.

Hasil pengujian anova pengaruh pemberian beberapa jenis pupuk terhadap tinggi Balangeran dapat dilihat pada Tabel 3.

Tabel 3. Anova pertambahan diameter anakan Balangeran.

\begin{tabular}{lcccccc}
\hline \multicolumn{1}{c}{$\begin{array}{c}\text { Sumber } \\
\text { Keragaman }\end{array}$} & Derajat & Jebas & Jumlah Kuadrat & \multirow{2}{*}{$\begin{array}{c}\text { Kuadrat } \\
\text { Tengah }\end{array}$} & F Hitung & \multicolumn{2}{c}{ F Tabel } \\
\cline { 5 - 7 } Kelompok & 4 & 0,00042 & 0,00011 & $0,600^{\text {tn }}$ & 3,84 & 7,01 \\
Perlakuan & 2 & 0,00029 & 0,00015 & $0,823^{\text {tn }}$ & 4,46 & 8,65 \\
Galat & 8 & 0,00141 & 0,00018 & & & \\
Total & 14 & 0,00213 & & & & \\
\hline
\end{tabular}

Sumber : data primer

Keterangan tn: tidak berpengaruh nyata

Tabel 3 menunjukkan bahwa F hitung < F tabel pada taraf 1\% dan 5\%, hal ini menunjukkan bahwa perlakuan dan kelompok tidak berpengaruh nyata terhadap pertambahan diameter tanaman Balangeran.

\subsubsection{Pertambahan jumlah daun}

Rata-rata pertambahan jumlah daun anakan Balangeran pada setiap variasi jenis pupuk dapat dilihat pada Gambar 3. 


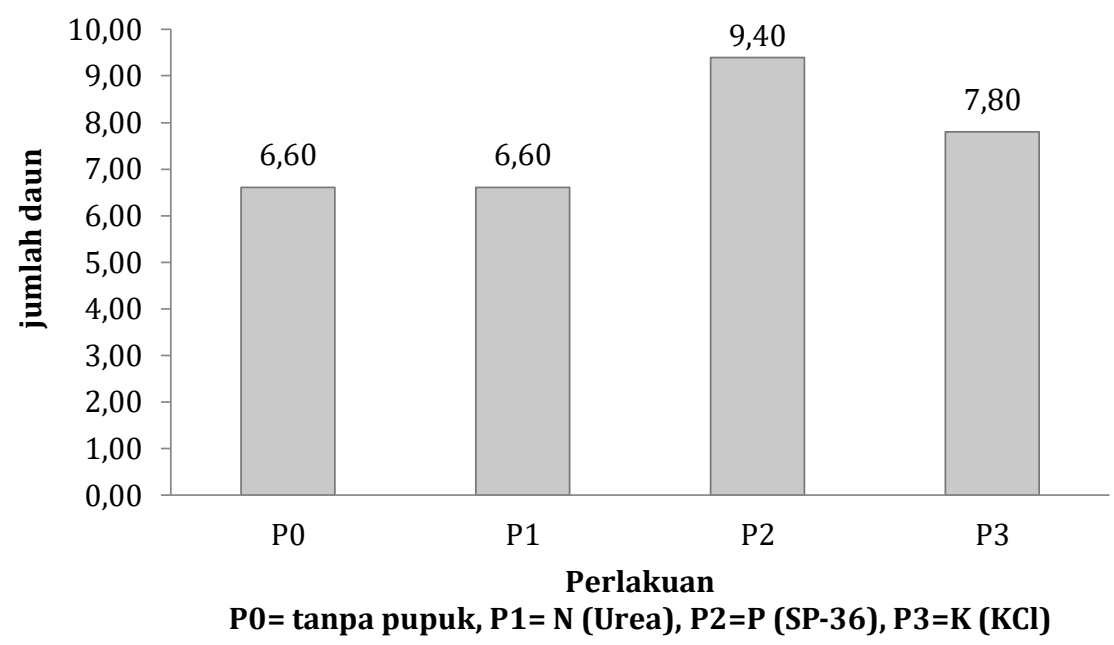

Gambar 3. Pertambahan rata-rata jumlah daun anakan Balangeran.

Berdasarkan Gambar 3, pemberian pupuk jenis P (P2) menunjukkan rata-rata pertambahan daun tanaman yang tertinggi yakni 9,40, kemudian diikuti pemberian jenis $\mathrm{K}(\mathrm{P} 3)$ sebesar 7,80 sedangkan pemberian pupuk $\mathrm{N}$ (P1) dan tanpa dipupuk menunjukkan rata-rata tinggi tanaman terendah dan sama. Pengaruh pemberian beberapa jenis pupuk terhadap pertambahan jumlah daun balangeran dapat dilihat pada Tabel $\mathbf{4}$ berikut.

Tabel 4. Anova pertambahan jumlah daun anakan Balangeran.

\begin{tabular}{lcccccc}
\hline \multicolumn{1}{c}{$\begin{array}{c}\text { Sumber } \\
\text { Keragaman }\end{array}$} & $\begin{array}{c}\text { Derajat } \\
\text { Bebas }\end{array}$ & $\begin{array}{c}\text { Jumlah } \\
\text { Kuadrat }\end{array}$ & $\begin{array}{c}\text { Kuadrat } \\
\text { Tengah }\end{array}$ & \multirow{2}{*}{ F Hitung } & \multicolumn{2}{c}{ F Tabel } \\
${ } }$ & 4 & 48.933 & 12.233 & $0.589^{\text {tn }}$ & 3.84 & 7.01 \\
Perlakuan & 2 & 19.733 & 9.877 & $0.475^{\text {tn }}$ & 4.46 & 8.65 \\
Galat & 8 & 166.277 & 20.783 & & & \\
Total & 14 & 234.933 & & & & \\
\hline
\end{tabular}

Sumber : Data primer

Keterangan tn: tidak berpengaruh nyata

Berdasarkan Tabel 4 diketahui bahwa perlakuan dan kelompok tidak berpengaruh nyata terhadap pertambahan jumlah daun anakan balangeran.

\subsection{Pembahasan}

Unsur $\mathrm{N}$ berperan penting dalam pembentukan atau pertumbuhan bagianbagian vegetatif tanaman seperti daun, akar, dan batang. Unsur P berperan dalam mempercepat pertumbuhan serta memperkuat jaringan tanaman agar tidak mudah roboh. Unsur $\mathrm{K}$ berperan membantu meningkatkan resistensi terhadap penyakit dan mengeraskan bagian kayu dari tanaman.

Hasil penelitian (Gambar 1) menunjukkan bahwa pemberian pupuk jenis P (SP-36) pertambahan tinggi rata-rata lebih tinggi dari jenis pupuk yang lain. 
Pemberian pupuk jenis $\mathrm{P}$ (SP-36) menunjukkan nilai rata-rata pertambahan tinggi lebih baik dari jenis lainnya, hal ini karena jumlah unsur $\mathrm{N}$ pada titik-titik pemberian pupuk jenis P yakni SP-36 pada tanahnya sudah mencukupi, hal ini sesuai dengan Homer (2008) bahwa kondisi pertumbuhan tanaman yang baik akibat tercukupinya hara $\mathrm{N}$ akan menyebabkan tanaman mampu menyerap $\mathrm{P}$ lebih efektif, selain itu kondisi ini mengindikasikan bahwa apabila tanah tidak mampu menyediakan unsur hara dalam jumlah yang cukup maka pemberian pupuk seperti jenis N, P dan K mampu menyediakan hara yang lebih cepat bagi tanaman.

Hasil penelitian diperoleh nilai koefisien keragaman (KK) yaitu 0,80\% dalam kondisi homogen. Berdasarkan Tabel 1 didapat bahwa perlakuan tidak berpengaruh nyata terhadap pertambahan tinggi, sedangkan pengelompokan berpengaruh sangat nyata, adanya pengaruh pada masing-masing kelompok merupakan salah satu faktor pertumbuhan. Junaedi (2009) menyatakan bahwa ada beberapa faktor yang berpengaruh terhadap keberhasilan pertumbuhan yaitu keadaan lingkungan berupa air dan unsur hara pada tanah, cahaya matahari, hereditas dan lainnya.

Pada Tabel 2 dapat dilihat bahwa kelompok 4 memberikan hasil yang cukup besar untuk pertambahan tinggi anakan Balangeran dibandingkan dengan jenis kelompok lainnya. Pertumbuhan tinggi anakan pada kelompok 4 yang lebih baik diduga ada hubungannya dengan meningkatnya ketersediaan unsur hara $\mathrm{N}$, $\mathrm{P}$ dan K pada media tersebut dibandingkan dengan kelompok lainnya

Hasil penelitian (Gambar 2), pemberian pupuk yang mengandung P yakni SP-36 menunjukkan pertambahan diameter lebih baik dari jenis pupuk lainnya, hal ini menunjukkan bahwa pemberian fosfor lebih baik dalam mendukung pertumbuhan, pernyataan tersebut didukung oleh Jumin (2002) yang menyatakan bahwa batang merupakan daerah akumulasi pertumbuhan tanaman khususnya pada tanaman yang lebih muda, sehingga dengan adanya perlakuan pemberian pupuk fosfor dapat mendorong laju fotosintesis dalam menghasilkan fotosintesis. Hasil fotosintesis tersebut akan ditranslokasikan ke semua organ tanaman tidak terkecuali ke bagian batang tanaman.

Rata-rata pertambahan diameter anakan dengan pemberian pupuk $\mathrm{N}$ yakni Urea lebih kecil dari perlakuan lainnya, sedangkan unsur $\mathrm{N}$ berperan dalam memacu pertumbuhan tanaman secara umum, terutama bagian vegetatif tanaman, selain itu juga berperan dalam pembentukan klorofil, asam amino, lemak, enzim, dan persenyawaan lainnya, tetapi menurut Lingga dan Marsono (1986) dalam Safutra (2012), jika tanaman kekurangan atau terlalu banyak unsur $\mathrm{N}$, maka akan memperlambat laju pertumbuhannya.

Tabel 2 menunjukkan bahwa perlakuan dan kelompok tidak berpengaruh nyata terhadap pertambahan diameter. Menurut Soekotjo (1976) dalam Irwanto 
(2006) bertambahnya diameter batang dipengaruhi oleh beberapa hal yakni permukaan tajuk, iklim dan kondisi tanah, kelembaban nisbi, dan sistem perakaran. Perubahan suhu akan mempengaruhi laju transpirasi yang ditandai dengan turunnya kelembaban udara relatif. Apabila hal seperti ini cukup lama berlangsung, dapat menyebabkan keseimbangan air tanaman terganggu dan dapat menurunkan pertumbuhan tanaman termasuk diameter tanaman.

Pada saat penelitian berlangsung ada pertambahan jumlah daun, namun di sisi lain terjadi pula pengurangan jumlah daun karena mati dan sebagian lagi mengalami kerusakan pada daun akibat terkena serangan hama penyakit, keadaan ini diduga dosis unsur hara $\mathrm{N}$ dan $\mathrm{P}$ yang diberikan masih kurang, sehingga daun tua menunjukkan gejala klorosis dan gugur sebelum waktunya, atau bisa pula disebabkan oleh dosis yang diberikan terlalu tinggi, sehingga menjadi racun bagi tanaman, khususnya berpengaruh terhadap daun sehingga menjadi mati. Soewandita (2008) menyatakan fungsi $\mathrm{N}$ adalah memperbaiki sifat vegetatif tanaman. Tanaman yang tumbuh pada tanah yang cukup $\mathrm{N}$, berwarna lebih hijau. Gejala kekurangan N, tanaman tumbuhan kerdil dan daundaun rontok dan gugur (Bennet 1996).

Lokasi penelitian Balangeran yang ditanam di hamparan lahan rawa gambut yang merupakan lahan bekas terbakar, menyebabkan beberapa tanaman masih ada yang tumbuh dan menyebabkan adanya naungan terhadap anakan. Hal lainnya yakni tumbuhnya gulma di sekitar anakan yang dapat menjadi pesaing tanaman Balangeran. Jenis tanaman yang mendominasi di areal penelitian yang tumbuh di sekitar anakan Balangeran adalah Mahoni (Swietenia mahagoni) dan Tumih (Combretocarpus ratundus), sedangkan untuk gulma di dominasi Ilalang (Imperata cylindrica).

\section{KESIMPULAN DAN SARAN}

Pertumbuhan anakan Balangeran dengan pemberian pupuk jenis tunggal dengan dosis 20 gr mampu meningkatkan pertumbuhan anakan. Pemberian jenis SP-36 menunjukkan rata-rata pertumbuhan lebih baik, tinggi $(1,26)$, diameter $(0,044)$, dan jumlah daun $(9,40)$ dibandingkan dengan pemberian pupuk Urea dan $\mathrm{KCl}$.

Jenis pupuk SP-36 dengan dosis 20 gr dapat digunakan sebagai perlakuan untuk anakan yang berumur 7 bulan, karena mampu meningkatkan pertumbuhan yang baik untuk tinggi, diameter dan jumlah daun.

\section{DAFTAR PUSTAKA}

Bennet WF. 1996. Nutrient deficiencies and toxicities in crop plants. APS Press. St. Paul Minnessota. 
Homer ER. 2008. The effect of nitrogen application timing on plant available phosphorus [Thesis]. Graduate School of the Ohio State University. Ohio.

Irwanto. 2006. Pengaruh perbedaan naungan terhadap pertumbuhan semai Shorea sp. di persemaian [Tesis]. Sekolah Pascasarjana, Universitas Gadjah Mada. Yogyakarta.

Jumin HB. 2002. Dasar-dasar agronomi. Rajawali Press. Jakarta.

Junaedi A. 2009. Pertumbuhan dan mutu fisik bibit Jabon (Anthocephalus cadamba) di polibag dan politub. Balai Penelitian Hutan Penghasil Serat Knok. Riau.

Lingga P dan Marsono. 1986. Petunjuk penggunaan pupuk. Penebar Swadaya. Jakarta.

Safutra RI. 2012. Kajian hasil-hasil penelitian tentang respon pemberian pupuk NPK terhadap pertumbuhan berbagai semai dan bibit tanaman kehutanan [Skripsi]. Fakultas Kehutanan, Institut Pertanian Bogor. Bogor.

Soekotjo W. 1976. Silvika. Fakultas Kehutanan IPB. Bogor.

Soewandita H. 2008. Studi kesuburan tanah dan analisis kesesuaian lahan untuk komoditas tanaman perkebunan di Kabupaten Bengkalis. Jurnal Sains dan Teknologi Indonesia 10(2):128-133.

Suryanto, Sasmito T dan Savitri HE. 2012. Budidaya Shorea balangeran di lahan gambut. Balai Penelitian Kehutanan Banjarbaru. Banjarbaru. 